\title{
Algunas consideraciones sobre el valor y su relación con la democracia y otros fetiches capitalistas
}

Andrés Piqueras Infante

doi: $10.34096 /$ cas.i49.6191

Universitat Jaume I. Castelló, España

Correo Electrónico: piqueraa@uji.es

\section{Resumen}

El artículo trata de mostrar la relación vinculante de las categorías básicas del modo de producción capitalista - la mercancía, el valor y la ganancia-, con la política como esfera artificialmente separada de la sociedad. Con ello se pretende desvelar por un lado la falsa apariencia de autonomía de la política en estas sociedades, y por otro las formas ilusorias de democracia que le acompañan, pues las exigencias del valor hecho capital prevalecen por encima de cualesquiera consideraciones sociales, políticas, morales, estéticas o religiosas.

Al estar atascadas en la actualidad las posibilidades objetivas de obtención de la plusvalía y de realización de la ganancia debido a la sobreacumulación de capital, se da en correspondencia un declive de las realizaciones democráticas - y especialmente de las opciones del reformismo- en la esfera política, en cuanto que ésta se manifiesta como expresión de la ley del valor.

\section{Considerations on value and its relationship with democracy and other capitalist fetishes}

\footnotetext{
Abstract

The paper intends to show the binding relationship that exists in the mode of capitalist production between merchandise, value and profit, as its basic categories, and politics as an artificially separated sphere of society. This is intended to reveal, on the one hand, the false appearance of the autonomy of politics in these societies, and on the other the illusory forms of democracy that accompany it, because the demands of value turned capital prevail above any social, political, moral, aesthetic or religious considerations.

Since objective possibilities of gaining surplus value and profitability due to capital overaccumulation are currently stuck, there is a corresponding decline in the democratic realizations - and especially in the options of reformism - in the political sphere, as the latter manifests itself as an expression of the law of value.
}

\section{Palabras clave}

Mercancía; Valor; Fetichización; Reformismo; Democracia
Key words

Merchandise; Value; Fetishization; Reformism; Democracy 


\section{Algumas considerações sobre o valor e a sua relação com a demo- cracia e outros fetiches capitalistas}

\section{Resumo}

Palavras-chave

Mercadoria; Valor; Fetichização; Reformismo; Democracia

1. Jeremy Bentham fue un jurista inglés al que se lo reconoce como precursor del utilitarismo. (continúa en página 43)

2. Es la famosa "mano invisible" de los clásicos, ligada también al utilitarismo, que se resume en que del interés egoísta personal deviene un "sano" interés colectivo. (continúa en página 43)

3. En todas las citas los énfasis son del original
O artigo procura mostrar a relação vinculante das categorias básicas do modo de produção capitalista- a mercadoria, o valor e o lucro-, com a política como esfera artificialmente separada da sociedade. Isso procura revelar, por um lado, a falsa aparência da autonomia da política nessas sociedades e, pelo outro, as formas ilusórias de democracia que o acompanham, porque as demandas do valor feito capital prevalecem acima de quaisquer considerações sociais, políticas, morais, estéticas ou religiosas. Uma vez que as possibilidades objetivas de ganhar valor excedente e rentabilidade devido ao excesso de acumulação de capital estão atualmente sujeitas, um declínio nas realizações democráticas é dado em correspondência -e, especialmente, as opções do reformismo- na esfera política, assim que se manifesta como uma expressão da lei do valor.

\section{Los fetiches de la sociedad capitalista}

Las raíces del fetiche de la democracia en la economía capitalista se encuentran en el supuesto intercambio libre de fuerza de trabajo por salario en la esfera de la circulación del capital.

La esfera de la circulación es aquella en la que se venden y se compran las mercancías producidas en la esfera de la producción.

Así lo expresó Marx:

La órbita de la circulación o del cambio de mercancías, dentro de cuyas fronteras se desarrolla la compra y la venta de la fuerza de trabajo, era, en realidad, el verdadero paraíso de los derechos del ser humano. Dentro de estos linderos sólo reinan la libertad, la igualdad, la propiedad y Bentham. La libertad, pues el comprador y el vendedor de una mercancía, v.gr. de la fuerza de trabajo, no obedece a más ley que la de su libre voluntad. Contratan como personas libres e iguales ante la ley. El contrato es el resultado final en que sus voluntades cobran una expresión jurídica común. La igualdad, pues compradores y vendedores sólo contratan como poseedores de mercancías, cambiando equivalente por equivalente. La propiedad, pues cada cual dispone y solamente puede disponer de lo que es suyo. Y Bentham, ${ }^{1}$ pues a cuantos intervienen en estos actos sólo les mueve su interés. La única fuerza que los une y los pone en relación es la fuerza de su egoísmo, de su provecho personal, de su interés privado. Precisamente por eso, porque cada cual cuida solamente de sí y ninguno vela por los demás, contribuyen todos ellos gracias a una armonía preestablecida de las cosas o bajo los auspicios de una providencia omniastuta, ${ }^{2}$ a realizar la obra de su provecho mutuo, de su conveniencia colectiva, de su interés social. (Marx, 1981, p. 138)

Pero las cosas cambian

al abandonar la órbita de la circulación simple o cambio de mercancías, adonde el librecambista vulgaris va a buscar las ideas, los conceptos y los criterios para enjuiciar la sociedad del capital y del trabajo asalariado, parece como si cambiase algo la fisonomía de los personajes de nuestro drama. El antiguo poseedor de dinero 
abre la marcha convertido en capitalista, y tras él viene el poseedor de la fuerza de trabajo, transformado en obrero suyo, aquél pisando recio y sonriendo desdeñoso, todo ajetreado; éste, tímido y receloso, de mala gana, como quien va a vender su propia pelleja y sabe la suerte que le aguarda; que se la curtan. (Marx, 1981, p. 138)

La fuerza de trabajo sólo puede presentarse al mercado laboral capitalista como una mercancía en cuanto que sea vendida como tal por su propio poseedor. El secreto de ello está basado en el proceso de desposesión o proletarización de las personas que es inherente al desarrollo histórico del capitalismo. Sin embargo, su pantalla o supraestructura filosófico-ideológica nos conduce al terreno contrario: más se desposee a la sociedad de los medios para vivir, más se ensalza la propiedad como sacrosanta (dado que para la reducida clase de quienes se apropian de esos medios - la burguesía o clase capitalista—, resulta vital que no se cuestione tal apropiación privada). Así, mientras una estricta minoría posee todos los medios de vida de la sociedad, la gran masa de población no tiene más propiedad que le sirva para vivir que su fuerza de trabajo; jamás una propiedad que le permita obtener capital (el capital es dinero que se valoriza a sí mismo, al invertirse para obtener plusvalía productiva mediante el trabajo ajeno). Quienes poseen la fuerza de trabajo y quienes poseen el capital se encuentran libremente en el mercado, unos como vendedores y otros como compradores. Ambos son, por tanto, personas jurídicamente iguales y libres de hacer lo que hacen.

De nuevo Marx:

Para que esta relación se mantenga a lo largo del tiempo es, pues, necesario que el dueño de la fuerza de trabajo sólo la venda por cierto tiempo, pues si la vende en bloque y para siempre, lo que hace es venderse a sí mismo, convertirse de libre en esclavo, de poseedor de una mercancía en mercancía. [...] La segunda condición esencial que ha de darse para que el poseedor del dinero encuentre en el mercado la fuerza de trabajo como una mercancía, es que su poseedor, no pudiendo vender mercancías en que su trabajo se materialice, ${ }^{4}$ se vea obligado a vender como una mercancía su propia fuerza de trabajo, identificada con su corporeidad viva. (1981, pp. 130-131)

Para poder vender mercancías distintas a su fuerza de trabajo, necesitaría poseer instrumentos de producción, materias primas, etc., algo reservado únicamente a unos pocos en la sociedad capitalista. Entonces, puesto que en ella los seres humanos quedan alienados del producto de su trabajo, pierden de vista las cantidades de trabajo concreto y hasta la propia concreción de trabajo que incorporan a las distintas mercancías y que los precios enmascaran. Tienden a concebir, por eso, al salario, al beneficio y a la renta como partes de la riqueza que producen el trabajo, el capital y la propiedad del suelo (o bienes inmuebles) respectivamente. Esta "fórmula trinitaria" de la alienación, implícita en la cosificación de las relaciones sociales capitalistas, hace que el valor de la fuerza de trabajo quede convertido a los ojos de la sociedad en "valor del trabajo", y por tanto, parezca que el salario pague este último, es decir, que el salario sea el cambio adecuado al trabajo realizado. La alienación inherente a este modo de producción está directamente vinculada, pues, a la enajenación que padecen los seres humanos respecto de los medios de producción, de su propia actividad y de su vida genérica, que se tiene que individualizar para sobrevivir como mera mercancía ("fuerza de trabajo"), o como elemento sustentador de esa mercancía (esto último conlleva para las personas su generización, o bien su etnificación, racificación... y en definitiva, su exogenización de los procesos productivos, como trabajo impago o semipago sostenedor de los mismos).

Estas condiciones elementales de alienación-enajenación hacen posible el arraigo y la propagación de los fetiches de la igualdad, la libertad y la democracia capitalistas en la esfera de la circulación de las mercancías. Es en ella, además, donde los individuos son
4. Es decir, no pudiendo vender los productos de su propio trabajo, porque al vender su fuerza de trabajo cede también cualquier derecho sobre ellos. Es decir que, en el capitalismo, la mayor parte de las personas no solo pierden los medios de producción y la posibilidad de trabajar para sí mismos de forma no dependiente; pierden también el producto de su trabajo. [Todas las notas hasta aquí son mías, no del texto de Marx]. 
5. Aquí se evidencia un grave problema de esquizofrenia social o de "democracia esquizofrénica". Por un lado, se hace ver a los individuos como soberanos (esfera de la circulación), por e otro no pueden sino someterse quienes les compran su fuerza de trabajo (esfera de la producción). imaginados como soberanos, protagonistas a partir de su capacidad de decisión en el consumo. Esto es, como consumidores pueden "elegir" y esto da la impresión de que también decidir (aunque, en realidad, solo puedan escoger entre las mercancías que el capital ha resuelto producir; igual que entre las opciones políticas que se les ofrecen, para que escojan de forma pasiva - como "electores", pues-).

En la esfera de la producción, en cambio, ninguno de esos fetiches puede mantenerse ni siquiera como ficción; pues en ella se muestra sin tapujos la desigualdad básica del capitalismo, entre quienes tienen los medios de producción (una estricta minoría) y quienes para vivir solo tienen su fuerza de trabajo (casi la totalidad de la sociedad). A estos últimos no les queda más "libertad", "democracia" o "igualdad" que trabajar subordinadamente para los primeros, o en todo caso, dependientemente respecto de sus decisiones y control económico. ${ }^{5}$

Por eso ha sido pieza clave de la tradición republicana señalar que cualquier persona dependiente no goza de autonomía propia. De hecho, los derechos civiles de la ciudadanía que se inauguró con el capitalismo fueron aceptados por la burguesía como "derechos pasivos", propios de una también ciudadanía pasiva. Mientras que los derechos políticos o "derechos activos" se los reservaba a sí misma la nueva clase dominante, pues el ciudadano pasivo está sometido a la necesidad del trabajo y, por tanto, a la servitus; está excluido por definición de la categoría de "personas libres". Así lo expresaba Constant: "[El trabajador asalariado] carece de la renta necesaria para vivir independientemente de toda voluntad ajena [...] y los propietarios son dueños de su existencia porque pueden negarles el trabajo" (citado en Losurdo, 2007, p. 189).

El mismo Kant lo había dejado ya medianamente claro: "[Para ejercitar los derechos políticos] se requiere una sola cualidad, a parte de la natural (que no sea niño o mujer), que sea su propio señor $y$, por consiguiente, que posea alguna propiedad [...] que le sustente" (citado en Kühnl, 1982, p. 56). De igual manera, el miembro de la llanura, Sieyès, compara a los no-propietarios con esclavos o niños, en cuanto que formaban parte de la gran familia del amo. Quizá por eso los levellers de la revolución inglesa se negaron a admitir en sus filas a los trabajadores dependientes, para terceros, porque carecían de libertad personal.

Transformar ese estado de cosas, conseguir la igualdad real de oportunidades solo podría ocurrir, por consiguiente, cuando ningún ser humano estuviera desposeído y, por tanto, a merced de otros para vivir (a expensas de ser contratado o no).

\section{Las luchas en torno a la explotación y la movilidad de la fuerza de trabajo}

Enfrentar y desbaratar las resistencias a la explotación y la subordinación u opresión, y al mismo tiempo hacer efectiva esa explotación (o que la subordinación se traduzca en explotación efectiva) han sido preocupaciones constantes para los poseedores de capital.

Desde los mismos inicios del capital mercantil estas se manifestaron en dos vertientes:

1. Cómo procurar fuerza de trabajo al menor coste posible para las principales actividades productivas.

2. Cómo retener o "fijar" a una mano de obra que se desliga poco a poco de los vínculos de vasallaje, esclavitud o servidumbre.

Resumimos cómo fueron afrontadas una y otra. 
1) La clave del capitalismo histórico ha sido disponer de, e incorporar permanentemente a la producción capitalista fuerza de trabajo exterior a ella, esto es, no producida ni reproducida bajo condiciones capitalistas, ${ }^{6}$ como la forma más barata de incluir trabajo vivo al modo de producción capitalista. Esto ha implicado a) la destrucción de economías precapitalistas, con la consiguiente "liberación" de ingentes cantidades de población listas para ser "movilizadas"; y b) la preservación artificial de formas no capitalistas de producción en el conjunto de las periferias (y durante mucho tiempo, la utilización de amplios núcleos de éstas como gigantescos "bantustanes"), como lugares de producción y reproducción de fuerza de trabajo bajo condiciones no capitalistas, listos para absorberla de nuevo cuando no se la requiera para la explotación capitalista (lo cual, en contrapartida, nunca estuvo libre de generar focos de resistencia étnicopopular, a menudo de forma endémica).

De ahí que el encauzamiento de la movilidad de la fuerza de trabajo y su forma de incorporación sean al menos tan importantes como la producción y realización de la plusvalía en las dinámicas de acumulación y desarrollo desigual capitalistas, ya que son condición imprescindible de su existencia.

En esa acumulación, es tan determinante incorporar la mano de obra directamente a través de su movilidad espacial o sectorial, como integrarla ocupacionalmente en la división social e internacional del trabajo, y utilizada a menudo como "materia prima" in situ, para ser aprovechada o importada después como "trabajo objetivado".

2) La movilidad tuvo que ser desde el principio o bien recortada en mayor o menor grado, o bien encauzada y en todo caso controlada para impedir la "salida" de los seres humanos de su condición de mercancía-fuerza de trabajo. Es decir, para asegurar y perpetuar su dependencia. Cuando esto no fue posible mediante el salario insuficiente, históricamente se recurrió a dos formas de sujeción:

1. absoluta (esclavismo y otras formas de trabajo forzado);

2. relativa o embridada. ${ }^{7}$ Entre sus formas más comunes encontramos el indeture o el engagement, la servidumbre, el peonaje, el trabajo de aprendizaje y las migraciones bajo contrato o religación al patrón.

Estas formas de impedimento de la movilidad se han impuesto allí donde las relaciones sociales de producción capitalista no consiguen suficiente grado de madurez como para desarrollar el campo de lo social con sus reconocimientos, intervenciones públicas y derechos en orden a permitir el trabajo dependiente asalariado como fuente de fijación eficaz por sí misma.

Con el desarrollo y madurez de esas relaciones sociales de producción, aquellas formas de impedimento irían poco a poco perdiendo importancia relativa a favor del trabajo dependiente asalariado (pero sin que las primeras desaparecieran y siempre complementando a este cuando y donde ha hecho falta); mientras que las "formas de movilidad primitivas" o "absolutas" exteriores a la reproducción del capital (la de seres humanos incorporados al proceso del valor del capital mediante su proletarización [De Gaudemar, 1979 y 1981]) dejarían paso a otras formas de movilidad internas al proceso de acumulación capitalista, que crecerían en importancia (movilidad relativa). Aunque por lo común al hablar de movilidad de la fuerza de trabajo se suele tener en cuenta únicamente la movilidad espacial, migratoria, lo cierto es que el capital utiliza esa movilidad al menos en cuatro sentidos:

a) Como adaptación a los diferentes requerimientos de la organización de los procesos de trabajo (distintas jornadas de trabajo, permutas en los puestos de trabajo o necesidades de la creciente división social y técnica del trabajo en general, en orden a aumentar
6. Por eso ha resultado siempre tan importante controlar la capacidad reproductiva de las mujeres, al mismo tiempo que la productiva (la pérdida de hombres a partir de la movilidad migratoria forzada o "libre", condujo a aumentar significativamente también su papel productivo). Aquel primer control fue objeto histórico de luchas de las mujeres, en forma de "huelgas de vientres", para no parir seres humanos en condiciones de esclavitud, servidumbre o, en general, sobreexplotación. Los puntos hasta aquí tratados son ampliamente desarrollados en el excelente trabajo de Potts (1990).

7. Embridamiento: cada vez que obstáculos de hecho y/o de derecho se oponen a la movilidad de la mano de obra, ya sea geográfica, sectorial, profesional, social o política. El economista Moulier-Boutang (2006) ha desarrollado tan implacable como minuciosamente el proceso de embridamiento de la fuerza de trabajo, o la forma en que el trabajo formalmente "libre" propio de la era capitalista (y ensalzado como tal por el ideario liberal) ha estado en realidad permanentemente sujeto a constricciones, de manera que su "libertad" es más la excepción que la norma. 
8. Los dos primeros tipos de movilidad han significado con frecuencia despidos, rotación de turnos, cambios forzados de puestos de trabajo o de actividad $y$, en general, un elevado conjunto de penalidades relacionadas con la subsunción real del trabajo al capital. En cuanto al tercer tipo de movilidad, parece innecesario insistir en la miserabilización que provoca en los seres humanos. la productividad o bien la plusvalía). Esto es, en pos del desplazamiento tecnológicoorganizativo del capital.

b) Como acoplamiento de la fuerza de trabajo a las demandas de unas u otras esferas o ramas de actividad, según expectativas de rentabilidad del capital.

c) Como desplazamiento dentro-fuera del trabajo asalariado (empleo-desempleo; economía formal-informal, etcétera). ${ }^{8}$

d) Como subordinación de la fuerza de trabajo a la propia movilidad espacial del capital y, dentro de ello, a sus dinámicas de concentración y centralización.

Así pues, en su conjunto, la movilidad de la fuerza de trabajo ha tendido a ser encauzada y sujetada en orden a conseguir su ductilidad, flexibilidad o subordinación adaptativa a las exigencias de acumulación de capital. Condición que entendemos como movilidad relativa (De Gaudemar, 1979), la cual se iría sumando a la movilidad absoluta con el desenvolvimiento del capitalismo y la consiguiente subsunción real del trabajo al capital. Es por eso que el estudio de la movilidad de la fuerza de trabajo no puede separarse del seguimiento de la puesta en práctica de las formas de trabajo y los cambios en los procesos organizativos de este, teniendo en cuenta que movilidad espacial y funcional se intersectan y combinan permanentemente en el modo de producción capitalista. De ahí que sea tan necesario, también, el estudio preciso de las formas de valorización del capital y sus consecuentes formas de movilidad del trabajo en cada momento histórico, a la hora de dar un sentido completo a los análisis migratorios.

De ahí también, en la otra cara de la moneda, la vital importancia no sólo del control del movimiento de la fuerza de trabajo o de los diferentes procedimientos de adquisición de ésta (dentro de los cuales, el trabajo asalariado es solamente una modalidad más, combinada históricamente con otras modalidades forzadas o semiforzadas de trabajo) (Van der Linden, 2008), sino su incorporación efectiva a los procesos de acumulación capitalista. De hecho, se ha llegado a enunciar que, frente a la baja tendencial de la tasa de ganancia, el capital (como capitalista colectivo) opone, entre otros dispositivos, la "ley de perfección tendencial de la movilidad del trabajo" (De Gaudemar, 1979, p. 236). Por eso es tan importante tener en cuenta los flujos migratorios en tanto que elementos de la producción de la mercancía fuerza de trabajo que se ha venido dando a lo largo del tiempo en las distintas formaciones sociales, y no sólo como componentes vitales de la circulación de tal mercancía. Cuanto más perfeccione o abarate los medios de transporte, más podrá beneficiarse el desarrollo capitalista del acceso a más y más fuerza de trabajo, en mercados cada vez más alejados. Especialmente si ese trasporte y sus costes corren a cargo de esta peculiar mercancía, única que puede desplazarse a sí misma o costearse su propia movilidad.

Pero es en el cuarto sentido, el de la movilidad del capital —el cual obliga a tomar en consideración el mercado global capitalista - en el que las migraciones internacionales de mano de obra proletarizada (asalariada) adquieren especial relevancia y visibilidad. No sólo como un dispositivo global de suministro de fuerza de trabajo, sino también de aportación de los elementos (étnicos, familiares, comunitarios, vecinales, etc.) de su propia reproducción. Desde esta perspectiva, las migraciones no pueden ser desligadas del análisis socioantropológico de cada formación social y de sus claves cultural-identitarias, ni se puede obviar la especial significancia que en los procesos migratorios adquiere el componente de género, tanto como el factor comunitario (sea étnico, nacional, local, etc.), los cuales a menudo se refuerzan (Piqueras, 2011).

Sin embargo, el capitalismo degenerativo actual se encuentra en una dinámica distinta, que acarrea necesidades y consecuencias de otro orden, y que están vinculadas al vertiginoso desarrollo de las fuerzas productivas habido con la Cuarta Revolución Industrial en curso, pues la exponencial tecnificación de los procesos productivos hace descartar más y más fuerza de trabajo de ellos. Las preocupaciones de la clase capitalista 
en la actualidad tienen que ver crecientemente, por tanto, con cómo "des-fijar" fuerza de trabajo de la producción al tiempo que se le sigue impidiendo su (libre) movilidad.

\section{Desarrollo de las fuerzas productivas y desvalorización de la fuerza de trabajo}

Para crecer de modo continuo, el capitalismo precisa desarrollar también de forma continua las fuerzas productivas, lo que ha conducido históricamente hasta hoy a un desarrollo tecnológico que lleva de la manufactura a la mecanización, de esta a la automatización y, por último, a la robotización de los procesos productivos.

Esto quiere decir que el desarrollo capitalista comporta una tendencial mayor utilización de - e innovación en- tecnologías intensivas en capital, o lo que es lo mismo, una menor utilización de fuerza de trabajo por unidad de capital invertido. Dicho de otra forma, el capitalismo presenta una tendencia a reducir el trabajo vivo en la producción directa.

Con las siguientes consecuencias:

a) La devaluación del trabajo vivo al reemplazarse el conocimiento directo de la fuerza de trabajo por maquinaria cada vez más sofisticada que acumula el saber colectivo de generaciones (la ciencia va más allá del trabajo colectivo para establecer un "trabajo universal", acumulado a lo largo de generaciones, y ha formado un stock de conocimiento libre que interviene crecientemente en la producción y que es apropiado privadamente por el capital [Martins, 2009]). Esto lleva a orientar la formación de la fuerza de trabajo en función del desarrollo tecnológico, con el objetivo -y la esperanza- de poder elevar su propio precio en el mercado laboral.

b) Una estructural tendencia hacia la eliminación de empleos (que da como resultado la necesidad de cada vez mayores aumentos del Producto Bruto Interno (PIB) para poder garantizar una creación de empleos equivalentes a los destruidos, lo que, a la postre, trae como consecuencia que en cada crisis capitalista se destruyan más empleos que los que son posteriormente recobrados).

c) Pero lo que es verdaderamente determinante es que aquella circunstancia lleva implícito un crónico proceso de sobreacumulación de capital invertido por unidad de valor que se es capaz de generar. ¿Qué significa esto? Que según aumenta el peso relativo del capital fijo (maquinaria) sobre el variable (seres humanos) en la composición orgánica del capital, puede aumentarse la productividad, pero menor valor ${ }^{9}$ (y, por tanto, ganancia) se es capaz de generar en proporción. Esto es, al reducirse relativamente la fuerza de trabajo en un determinado proceso productivo, se reduce también la masa de valor representada por ella (en cuanto que plusvalor, porque este solo se extrae de los seres humanos), con lo que cada vez queda menos margen para que los aumentos de la productividad repercutan en la elevación de la tasa de plusvalía. Por eso, llega un momento en que los caminos de la productividad y de la ganancia dejan de ir paralelos e incluso pueden entrar en contradicción. Lo explicamos.

Según la automatización de los procesos productivos va haciendo que la cantidad de tiempo de trabajo depositada en cada producto sea menor, la productividad de cada trabajador debe aumentar (debe "hacer" más productos o servicios en la misma unidad de tiempo) para que la masa de beneficio realizable no disminuya (es decir, si ahora una mercancía sale con una décima parte del valor que tenía hace una década, han de fabricarse 10 veces más elementos de esa mercancía para no perder el total del valor anterior y, por tanto, la posibilidad de ganancia capitalista). Lo cual conduce a la paradoja de que, cuanto más aumenta la productividad de las fuerzas productivas, más se necesita que aumente para intentar salvar el beneficio. Así, si la productividad crece, por ejemplo, un 5\%, la acumulación ha de crecer al mismo nivel para mantener
9. El valor de una mercancía (sea objeto o servicio) es el tiempo socialmente necesario para producirla. Para un amplio detalle de las circunstancias del valor tengo que remitir a Piqueras (2017 y 2018) 
el empleo (y, en consecuencia, las posibilidades de plusvalía). Pero para ello, el consumo se ha de intensificar exponencialmente de cara a adaptarse a los aumentos de productividad y en forma paralela elevación de la producción. El capitalismo, entonces, está condenado a mantener una continua expansión del consumo a escala planetaria, lo que le obliga al logro de una pulsión consumista en las poblaciones (al menos, en las que tienen una cierta capacidad de compra) y lleva a una permanente pugna entre los capitales por expandir el mercado y apropiarse de una mayor cuota de este, lo que, de paso, y contradictoriamente, expulsa a más población del mercado.

Con la actual revolución científico-técnica aplicada a la producción, el tiempo de trabajo socialmente necesario se reduce al límite, por lo que cada vez el trabajo inmediato humano guarda menos relación con la producción de riqueza, y con ello se da una creciente pérdida de valor en las nuevas fuerzas que animan la producción y generan la riqueza material e inmaterial. "El valor se hace más anacrónico en términos del potencial de producción de riqueza [...] de las fuerzas productivas a las que da origen" (Postone, 2006, p. 270). Esto entraña enormes consecuencias en un modo de producción que se basa precisamente en la producción de valor (riqueza abstracta) antes que en la de riqueza material y social, como es el capitalista. Sus relaciones sociales de producción, su racionalidad o razón de ser, se convierten cada vez más en una rémora para el progreso humano.

En un determinado nivel del desarrollo tecnológico, la expansión del mercado ha ido acompañada a su vez de nuevas posibilidades de incorporación de fuerza de trabajo a los procesos productivos, con lo que se garantizaba de nuevo la reproducción del valor, en lo que parecía un ciclo virtuoso indestructible. Sin embargo, sobrepasado un cierto límite de desarrollo de las fuerzas productivas, con la revolución científico-técnica actual, la eliminación de la fuerza de trabajo supera las posibilidades de expansión del capital (que debería producir y vender mercancías tendiendo a infinito según el valor de cada una de ellas va tendiendo a un tiempo menor) (Piqueras, 2017 y 2018). Hoy el mercado ya se ha hecho planetario y no puede agrandarse ni por asomo al ritmo al que aumenta la productividad con la automatización de los procesos productivos. Al tiempo, al incrementarse exponencialmente la composición orgánica del capital (capital fijo o máquinas sobre capital variable o seres humanos), incluso las nuevas posibles expansiones del mercado no conllevan una incorporación paralela de fuerza de trabajo, dados los altísimos niveles de productividad alcanzados. Es decir, el ritmo de crecimiento del trabajo productivo, desde el punto de vista de valorización del capital, no se compagina con el nivel de crecimiento de la productividad. Y por tanto, la tasa de ganancia (vinculada necesariamente a la cantidad de valor incorporada en cada proceso productivo) desciende a un ritmo tal que arrastra a la masa de ganancia global (la masa global de valor comienza a decaer: el beneficio no compensa el capital total invertido). Además, si con ello se deja a más parte de la población sin empleo, y por tanto con una marcada tendencia a su pauperización, como veremos enseguida, más difícilmente el mercado podrá siquiera expandirse en alguna medida.

\section{Desvalor de los seres humanos y acentuación del despotismo de las relaciones laborales}

Podemos entender el desvalor de los seres humanos en cuanto que fuerza de trabajo de dos formas diferentes pero complementarias: a) como pérdida de las posibilidades de generar valor o de contribuir a este; b) como pérdida de la propia importancia en el proceso de generación o reproducción de valor.

Las "capacidades" del capital, especialmente el que queda denominado como "capital fijo", nos asombran tanto porque el capitalismo nos ha habituado a mirar el mundo de 
forma invertida, como a través de una cámara oscura, pues aquellas no son sino la forma fetichizada de los poderes del trabajo social colectivo, que incorporan las experiencias y saberes de generaciones; hoy diríamos que es la forma sistematizada de conocimiento que se deposita como "ciencia". Esa incorporación fue hecha de forma progresiva, y ha implicado una dimensión creciente de la subsunción real del trabajo al capital. Así, mediante la cooperación productiva, los conocimientos y experiencias de los productores y productoras inmediatos fueron incorporados al proceso general de trabajo, lo que ha dado como resultado una primera división del tiempo de trabajo mediante la especialización. Con la maquinización, son los conocimientos y experiencias generales de la sociedad los que resultan incorporados a la producción (la capacidad del conjunto social, expresada como maquinaria, se va a poner a producir a expensas de la capacidad de cada individuo, que se convierte en mero servidor de la máquina, lo que lleva a la mutilación de sus facultades). Es por eso que aumenta la autovalorización del capital al tiempo que disminuye el valor de la fuerza de trabajo como mercancía, en cuanto que pierde importancia en el proceso general de procuración de valor.

En la actual revolución científico-técnica, el proceso de trabajo queda cada vez más dependiente del acelerado avance de la tecnología para los procesos de valorización. El general intellect (objetivado en máquinas autómatas o robóticas) hace más y más prescindibles a los seres humanos en los procesos de trabajo (Macías, 2017).

Esto se traduce, entre muchas otras consecuencias, en una palmaria relación de poder (que incrementa el poder de clase del capital).

Efectivamente, la automatización en curso afecta de modo negativo a la organización de la fuerza de trabajo, lo que refuerza como contrapartida el poder y control de la supervisión, haciendo más y más fácil la monitorización de la actividad laboral y socavando al mismo tiempo las posibilidades de solidaridad entre la población trabajadora. Estas circunstancias imprimen una tendencia al aumento del despotismo patronal, no sólo según se debilitan las formas organizativas del trabajo, sino según crece el ya de por sí ingente ejército laboral de reserva mundial y se obstaculiza, por otra parte, la fluida consecución de la ganancia.

Por eso el desempleo masivo estructural es acompañado de otro conjunto de medidas tendientes a rebajar la capacidad antagonista de las organizaciones de clase y el poder social de negociación de la fuerza de trabajo a límites mínimos (a ello estuvo orientada la ofensiva neoliberal): a) ataque a los derechos colectivos de la población asalariada; b) extensión de la jornada y de la intensidad del trabajo sin la correspondiente elevación del salario; c) profunda reestructuración productiva en orden de aumentar, tanto la velocidad de rotación del capital (acortamiento del tiempo desde que se producen la mercancías hasta que se venden), como la desorganización y debilidad de la fuerza de trabajo. Todas estas medidas conducen a la mayor explotación ${ }^{10}$ y a la devaluación o desvalorización del “trabajo vivo” también por su precio.

Las secuelas para la población de que sea la tasa de explotación la que palie la pérdida de valor de la economía capitalista son, como puede fácilmente deducirse, terribles.

Para empezar, la precariedad laboral resultante es del todo patente en aspectos como: a) la temporalidad laboral; b) la importancia de las modalidades de trabajo sin relación contractual y a menudo tampoco salarial; c) la creciente extensión de la figura de los "falsos autónomos"; d) la enorme dimensión de la economía sumergida; e) las peores condiciones laborales en relación con aspectos tales como los bajos salarios, el desajuste entre la formación adquirida y el puesto de trabajo desempeñado, la prolongación de la jornada laboral (a menudo sin compensación económica) y la flexibilidad horaria, así como la elevada incidencia de la siniestralidad laboral; f) el menor acceso a la
10. "Ley” ya anunciada por Marx en los Grundrisse: "El tiempo de trabajo como medida de la riqueza pone la riqueza misma como fundada sobre la pobreza y al disposable time como existente en y en virtud de la antítesis con el tiempo de plustrabajo, o bien pone todo el tiempo de un individuo como tiempo de trabajo y consiguientemente lo degrada a mero trabajador, lo subsume en el trabajo" (1972, p. 596). Por eso, si el desarrollo tecnológico acorta el tiempo socialmente necesario para la producción, esto no se traduce en más tiempo libre proporcional, sino ante todo en la expulsión de seres humanos de los procesos productivos, $y$ en el sobre-trabajo de los que todavía permanecen en ellos. 
11. Estas circunstancias han sido descritas por Martin y Prieto (2015) como "empleo precario y desempleo activo" (p. 19), que tienen que ver con la amplia combinación de multivariadas formas de empleo y de explotación sin empleo que hoy tiene lugar por doquier. protección social; y g) una tutela colectiva debilitada por el recorte de los derechos protegidos por las normas internacionales de trabajo, incluidos los de libertad sindical, negociación colectiva y protección contra el acoso y la discriminación (datos de estos puntos en Piqueras, 2017).

$\mathrm{Si}$, como hemos visto, el desarrollo tecnológico hace a los seres humanos cada vez más innecesarios o superfluos para los procesos productivos; si además, la tecnología se hace la forma universal de la producción material, esta circunscribe una totalidad histórica en la que se llega al paroxismo de la desposesión de los desposeídos: se los desposee también de su fuerza de trabajo como elemento requerido por el capital (lo único que podrían vender para sobrevivir). Y ya se sabe que, en el capitalismo, lo que no es fuente de plusvalía no tiene valor.

Por eso, la ansiedad por no caer en el pelotón de los desechados obliga a una constante puesta al día del yo, un denuedo diario por adquirir destrezas, conocimientos o preparación que se escapen al radio de acción de la automatización, como objetivos móviles que quedan obsoletos nada más adquiridos. Eso significa poner la vida en permanente disponibilidad para la explotación, no importa si una creciente parte del trabajo que se realiza en el ámbito laboral no sea remunerada. Aquí hay que contar no solo el trabajo que las personas llevan a cabo sin pago (horas extras no pagadas, mucho del tiempo trabajado por medio de contratos en formación, trabajo de becarios, etcétera), sino el que realizan para valorizarse a sí mismas en el mercado laboral o para asistir a entrevistas, desplazarse en busca de oportunidades, conectarse, estar al tanto de las últimas tendencias. ${ }^{11}$ Hay una creciente obsesión por la autovalorización, consecuente con un mercado que desvaloriza continuamente la formación adquirida, que deja obsoletas a toda velocidad las aptitudes y habilidades, lo que puede describirse como obsolescencia programada del currículum. Lo cual puede entenderse, a la vez, como la otra cara de la curriculización de la vida o el intento de traducir todo lo que se hace en términos de currículum profesional (esto es, traducido a posibilidad de extracción de valor), ante la acuciante angustia de perder valor como seres humanos. Cada vez más lejos de ser sujetos, somos más bien proyectos vendibles.

Esto, que entraña en sí mismo una "precariedad subjetiva", hace que lo que antes se veía como dominación se experimente ahora como procesos objetivos frente a los que no hay alternativa. La tendencia a la sobreexplotación, unida a la conectividad permanente, la disponibilidad y la curriculización del tiempo de vida, tienen por tanto otras secuelas, pues obstaculizan la participación vecinal, comunitaria, social y política, y muy a menudo también distorsionan o entorpecen las relaciones íntimas, de pareja, familiares y amicales de la fuerza de trabajo. Aislada o volcada a la supervivencia diaria en el mundo laboral, trabajando a veces sin empleo e incluso sin salario, desconectada de la comunidad, se ve fácilmente abocada a la individuación de su vida y de su poder de negociación, así como a la desconexión política (lo que a menudo entraña un analfabetismo político proclive a redundar a su vez en la negatividad de los otros procesos).

En suma, en el capitalismo terminal, los seres humanos: 1) son desenganchados absoluta o relativamente de los procesos productivos, y por lo tanto, de la relación capitalista básica, la del trabajo abstracto (asalariado) para la producción de mercancías; 2) se hacen redundantes o sin valor (desechables); 3) su acentuada (re)proletarización y todo el conjunto de limitaciones a la libre movilidad en el sistema mundial capitalista los inmoviliza e incapacita crecientemente para transformar su propio proceso de desvalorización.

Con ello, además, la ciudadanía mediante el empleo, la "ciudadanía industrial" propia del capitalismo "regulado-keynesiano" se deshace, y la sociedad se va diluyendo. 


\section{Las formas fantasmagóricas de la democracia en el capitalismo terminal}

Hemos visto cómo, a partir de un supuesto desarrollo de los fetiches materiales del capital (salario, beneficio, renta), se han desarrollado sus fantasmagóricos correlatos sociopolíticos: "libertad", "igualdad", "democracia".

Por eso hemos llegado a esa "extraña” situación, en que cuanto más se dificultan o entorpecen las dinámicas del valor, cuanto menos valor entrañan los seres humanos y cuanto más se sujeta su "libertad" (que en este caso hemos tratado sobre todo en cuanto movilidad ${ }^{12}$ y condiciones laborales), más las distintas expresiones ideológicas de la supraestructura capitalista se empeñan en encauzar la atención hacia lugares inexistentes y paisajes imposibles. Es decir, se esfuerzan en hacer de las ideas la base de la realidad.

Por eso, cuando jamás el mundo fue tan desigualitario en la historia de la humanidad como en el presente, se multiplican las proclamas idealistas. Más se habla de "derechos humanos", "desarrollo" y "cooperación”, más millones de personas quedan sin posibilidades de vida y forzadas a saltar las vallas y muros que rodean a las "islas" donde se da la concentración y centralización del capital en el mundo. Igualmente, más se incluye la paz en los programas educativos y se promueven conferencias sobre ella, más armas de destrucción total se esparcen por el mundo y más guerras o situaciones de guerra se abren por doquier, mientras la represión, a menudo el paramilitarismo y la masacre, la desaparición y tortura de las propias poblaciones, se extiende por la mayor parte de países. Más se discursea y escribe sobre ética en general, más corrupto se hace el sistema; más se predica en concreto la ética empresarial, más se embrutecen las condiciones del mercado laboral. ${ }^{13}$ Es como si el propio sistema secretara este tipo de discursos o ideologías para alejar la atención de sus propias entrañas, como hace el calamar cuando suelta su tinta. Porque partir para el análisis y transformación del mundo, de lo que muestra la apariencia ("igualdad formal de los individuos", por ejemplo) es garantía, cuanto menos, de inocuidad política o inutilidad social.

Solo teniendo en cuenta esta inversión de los principios causales y la confusión de los postulados con realidades, se entiende que al menos algunas de esas expresiones supraestructurales crean que las transformaciones de gran calado a las que apuntan sus ideales regulativos sean posibles dentro del orden capitalista.

Manteniendo esta paradójica correspondencia con la degeneración social, y en la misma línea de evasión de la realidad, el mainstream de la sociología y la antropología social se ha puesto manos a la obra para hacer valer a los individuos como "soberanos", desarrolladores de "estrategias", conformadores de "singularidades", diseñadores de sus propios "estilos de vida", fecundadores de diminutas - y fácilmente cambiantes"culturas" que se convierten por sí mismas, de modo inverosímil, en agentes sociales. En un movimiento de contradicción consigo misma, la ciencia social dominante pretende de nuevo hacer prevalecer lo individual sobre lo estructural, para recuperar la importancia de lo micro, del individuo, de las identidades que brotan en la superficie del entramado social (en vez de indagar sus conexiones profundas y no visibles con el valor - que sí que es la base práctica de este sistema-, con el papel que se juega en torno a él y el conjunto de relaciones sociales que de ahí y de otros procesos estructurales se desatan y envuelven a los individuos, a sus colectividades y a sus relaciones). La psicologización de las relaciones sociales es congruente con el renovado protagonismo de la intervención psicológica sobre la sociológica y la sociopolítica a la hora de abordar las cuestiones sociales y, de paso, recuperar así a los individuos como células autorreguladas del metabolismo capitalista.
12. De hecho, la libre y amplia movilidad se convierte en un cada vez más importante elemento de distinción de clase (Boltansky y Capello, 2002).

13. Curioso, según se eliminan dispositivos jurídicos vinculantes sobre las relaciones y derechos laborales, según se descuartiza la negociación colectiva, se introducen más y más elementos "éticos" que no conllevan ninguna obligatoriedad legal, y cuyo criterio está sujeto a alguna supuesta autoridad entendida en ética. Este "esfuerzo ético" se compagina con la ergonomía en los centros de trabajo, para conseguir la colaboración y el compromiso de los trabajadores y hacer de ellos individualidades de las que se puede eliminar cualquier negatividad -resistencia-con el objeto de potenciar su máxima productividad. 
14. La identidad revolucionaria ha quedado impresa en la Modernidad; está vinculada a los dos pilares fundamentales de esta, la racionalidad y la emancipación, que a su vez se relacionan con las osadas pretensiones de protagonismo del ser humano en su propia vida y con su asumida capacidad de transformar la historia. La

"identidad revolucionaria" necesita de la autenticidad como forma de vida con la que enfrentarse a una realidad que desagrada, y al tiempo como una manera de crear comunidad a partir de compartir esas claves, paliando así, mediante identidades políticas, la destrucción de los vínculos comunales y artesanales que trajo el capitalismo (Piqueras, 2004. Ver también Moscoso y Sánchez, 2017).
Pero cualquier posibilidad de ajustar análisis e ideales igualitarios pasa por el (re) conocimiento de una realidad (capitalista) estructuralmente desigualitaria, basada en la explotación del ser humano por el ser humano, que (por ello mismo) levanta permanentemente en su seno antagonismos, al tiempo que "produce" individuos-mercancía, hoy ya con cada vez menos valor.

Por eso es de interés aportar algunas consideraciones que vinculen lo ideal a lo estructural (lo que llamamos "materialismo dialéctico"). A lo largo del capitalismo histórico encontramos tres factores materiales o estructurales relacionados con la apertura o el cierre democrático (y por lo tanto, con las reformas en favor de las grandes mayorías) de este modo de producción:

1. Un factor subyacente. Se da cuando aumenta la masa de ganancia y, con ella, la tasa media de beneficio.

2. Un factor activante. Que la clase capitalista se vea con dificultad de reemplazar o sustituir a la fuerza de trabajo; es decir, que se agote el ejército laboral de reserva.

3. Un factor precipitante. Concurre cuando la fuerza de trabajo organizada adquiere una fuerza política importante (las posibilidades de este último factor están a su vez profundamente vinculadas a las del factor activante y vienen condicionadas también por el factor subyacente).

Esos tres factores, y con ellos las posibilidades de avanzar en espacios democráticos y de derechos, se abrieron en el capitalismo industrial con las luchas históricas porque aquel era un (nuevo) modo de producción que irrumpió desarrollando aceleradamente y en escala desconocida hasta entonces las fuerzas productivas, y con ellas, el desarrollo de la conciencia humana y social (la mente humana es una fuerza productiva de primer orden). Esa propia conciencia llegó a transformarse en conciencia revolucionaria, y les dio, por primera vez, la osadía a los seres humanos de intentar dotarse intencionalmente de un modo de producción (además, uno orientado a acabar con la explotación del ser humano por el ser humano, en el que los medios de producción estarían distribuidos para el conjunto de la sociedad: el socialismo). ${ }^{14}$ La Revolución Soviética fue hasta ahora el culmen de esas aspiraciones. Su existencia cambió el propio decurso del capitalismo, y provocó en él una mutación extraordinaria (al menos en sus centros y con menor fuerza en bastantes de sus periferias): la opción reformista o capitalismo social organizado y su "Estado de Bienestar" (para una explicación histórica, Piqueras, 2014 y 2015).

Sin embargo, en su decadencia o morbidez, y ya sin la Unión de Repúblicas Socialistas Soviéticas (URSS), el capitalismo ya no sólo no es susceptible de generar "progresismo" alguno, sino que su tendencia es a destrozar lo conseguido, a involucionar profundamente en todos los campos (recordemos que si se obstruye la dinámica del valor, el armazón que lo sustenta, la sociedad, también). Ninguno de los tres factores estructurales mencionados se da en la actualidad y difícilmente podrán ya darse en un capitalismo degenerativo.

Las formas fantasmagóricas de la socialdemocracia, esto es, las presentes opciones políticas que nos hablan de "recuperar los derechos sociales", de "trabajar para lograr el pleno empleo", de "conseguir mayores cuotas de igualdad", etcétera, son mera tinta de calamar, pues al obstaculizarse el valor como plusvalor, las clases capitalistas mundiales tienen necesariamente que descartar la opción socialdemócrata, ya que no pueden redistribuir apenas ganancia real (y además, cuentan a su favor con un ejército de reserva hoy de dimensiones mundiales y una profunda debilidad sistémica de la fuerza de trabajo). Toda su obsesión, que les lleva también a una cada vez más mortal pugna entre sí, en adelante, será apropiarse del cada vez menor plusvalor que va quedando, y desposeer a las sociedades de la riqueza social hasta ahora generada, tanto en forma 
de servicios sociales, como en bienes comunes, o en el propio hacer en común de los seres humanos, así como en infraestructuras y sectores estratégicos que hasta hace poco eran "nacionales" o públicos (es lo que se ha descrito como crecimiento por desposesión... y que yo he llamado también proceso de autofagocitación, que implica una brutal reproletarización de las poblaciones [Piqueras, 2015 y 2017]). ${ }^{15}$ Porque no solo las personas tenemos cada vez menos importancia en el modo de producción capitalista. Las sociedades también.

Difícilmente, en consecuencia, se puede "regenerar" sociedad, ni forjar el valor de las personas y de sus colectivos y versiones identitarias, si no se afecta la raíz de su constitución, que cada vez más nos hace insustanciales, insignificantes ( $\sin$ valor); esto es, prescindibles.

Es por eso también que filosofías, disciplinas académicas enteras como la economía, propuestas teóricas y modas ético-místicas en general, se autoagotan en el nivel moral o normativo, al tomar como puntos de partida situaciones inexistentes y proponer metas u opciones ideales dentro del capitalismo, a partir del supuesto desarrollo de los fetiches materiales de este.
15. Esto es, los capitalistas que se van apropiando de la trama del mundo de la vida y la mercantilizan, se quedan con una proporción de los salarios (que es la parte del valor generado que se devuelve a la fuerza de trabajo y que esta ahora tendrá que retornar en gran medida debido al pago de actividades que han sido privatizadas); y también con parte del valor como plusvalor obtenido por otros capitalistas (que también tienen que pagar por las nuevas "mercancías"). Es decir, capitalistas particulares se apropian de una mayor parte del valor total generado, y en consecuencia realizan algo así como una "cosecha del valor" (Hanlon, 2014). Para ello rentabilizan en beneficio propio una enorme cantidad de trabajo gratis realizado por la sociedad. Esto no deja de ser un proceso de fagocitación de la riqueza y del valor ya generados, sin apenas nueva generación de una y otro; es decir, una autofagocitación (que bien puede ser nombrada también como suicidio).

1 Jeremy Bentham fue un jurista inglés al que se lo reconoce como precursor del utilitarismo. Los seres humanos se mueven por el principio de la mayor felicidad en un exclusivo sentido hedonista, el cual marca el criterio de todas sus acciones, tanto privadas como públicas. Según él, la corrección de toda acción se mide por su utilidad de cara a ese principio. Toda la economía vulgar que se desarrollaría desde el siglo XIX compartiría el patrón subjetivo para analizar cualquier proceso económico (una economía subjetivista en la que el valor viene determinado por las preferencias de los individuos o "utilidades" de las mercancías respecto de esas preferencias). "Un genio de la tontería burguesa", lo llamó Marx. (En página 32.)

2 Es la famosa "mano invisible" de los clásicos, ligada también al utilitarismo, que se resume en que del interés egoísta personal deviene un "sano" interés colectivo. Creencia que va a contrapelo de cualquier evidencia, pues la constitución y pervivencia de las sociedades es solo posible cuando lo personal se pone en función de lo colectivo. Por eso la puesta en práctica del interés personal como sustentador de la sociedad da paso a las abismales desigualdades de las sociedades capitalistas actuales, así como a su resquebrajamiento. (En página 32.) 


\section{Q Referencias bibliográficas}

» Boltanski, L. y Chiapello, È. (2002). El nuevo espíritu del capitalismo. Madrid: Akal.

»De Gaudemar, J-P. (1979). Movilidad del trabajo y acumulación de capital. México DF: Era.

» De Gaudemar, J-P. (1981). La movilización general. Madrid: La Piqueta.

» Hanlon, G. (2014). The entrepenurial function and the capture of value: Using Kirzner to understand contemporary capitalism. Ephemera. Theory and Politics in Organization, 14(2), 177-195.

» Kühnl, R. (1982) [1971]. Liberalismo y fascismo. Dos formas de dominio burgués. Barcelona: Fontanella.

》 Losurdo, D. (2007). Contrahistoria del liberalismo. Barcelona: El Viejo Topo.

» Macías, A. (2017). El colapso del capitalismo tecnológico. Madrid: Escolar y Mayo.

» Martín, E. y Prieto, C. (Coords.) (2015). Conflictos por el tiempo. Poder, relación salarial y relaciones de género. Madrid: CIS y Universidad Complutense.

» Martins, C. E. (2009). A teoria da conjuntura e a crise contemporânea. Polis, 24, 385-401.

» Marx, K. (1972) [1858-1859]. Grundrisse. Elementos fundamentales para la crítica de la economía política [Borrador] 1857-1858. Vol. II. Madrid: Siglo XXI.

» Marx, K. (1981) [1867]. El Capital. Crítica de la economía política. Tomo 1. La Habana: Editorial de Ciencias Sociales.

» Moscoso, L. y Sánchez, P. (2017). Encrucijadas del entusiasmo: la transmisión de la experiencia revolucionaria, 1789-1917. En J. Andrade y F. Hernández (Eds.), 1917. La Revolución rusa cien años después (pp. 53-82). Madrid: Akal.

» Moulier-Boutang, Y. (2006). De la esclavitud al trabajo asalariado. Economía histórica del trabajo asalariado embridado. Madrid: Akal.

» Piqueras, A. (2004). Sobre culturas e identidades en la mundialización capitalista. Acta Sociológica (n⿳亠丷a época), 41-42, 135-171.

»Piqueras, A. (2011). Significado de las migraciones internacionales de fuerza de trabajo en el capitalismo histórico. En A. Piqueras y W. Dierckxsens (Eds.), El colapso de la globalización. La humanidad frente a la gran transición. Barcelona: El Viejo Topo.

» Piqueras, A. (2014). La opción reformista. Entre el despotismo y la revolución. Una explicación del capitalismo histórico a través de las luchas de clase. Barcelona: Anthropos.

" Piqueras, A. (2015). Capitalismo mutante. Crisis y lucha social en un sistema en degeneración. Barcelona: Icaria.

» Piqueras, A. (2017). La tragedia de nuestro tiempo. La destrucción de la sociedad y la naturaleza por el capital. Análisis de la fase actual del capitalismo. Barcelona: Anthropos.

» Piqueras, A. (2018). Las sociedades de las personas sin valor. Barcelona: El Viejo Topo.

»Postone, M. (2006) [1996]. Tiempo, trabajo y dominación social. Una reinterpretación de la teoría crítica de Marx. Madrid: Marcial Pons.

» Potts, L. (1990). The World Labour Market. A History of Migration. Londres-New Jersey: Zed Books.

» Van der Linden, M. (2008). Workers of the World: Essays Toward a Global Labor History. Brill: Princeton University Press. 